\title{
Damping properties of para-phenylene terephthalamide pulps modified damping materials
}

\author{
Baihua Yuan', Meng Chen², Yu Liu', Shexu Zhao' \\ and Heng Jiang ${ }^{2}$
}

\begin{abstract}
A series of para-phenylene terephthalamide pulp modified damping materials were prepared. The dynamic mechanical properties, differential scanning calorimetry, vibration damping properties, vulcanization property, tensile strengths as well as scanning electron microscopy micrographs of the damping materials were studied theoretically and experimentally. The dynamic mechanical properties of para-phenylene terephthalamide pulp modified damping materials were also compared with aramid short-cut fiber, E-glass staple fiber and carbon fiber powder modified damping materials. The results showed that para-phenylene terephthalamide pulp modified damping materials exhibited the best damping property and highest modulus in comparison with the other types of fibers. The storage modulus ( $\left.E^{\prime}\right)$, loss modulus $\left(E^{\prime \prime}\right)$ and tensile strength of the materials were all increased significantly with increasing pulp content, and this trend was significantly greater in machine direction rather than in cross-machine direction. The second, third and fourth modes modal loss factors $(\eta)$ of the steel beams coated with para-phenylene terephthalamide pulp modified damping materials increased substantially up to a maximum, and then became stable with increasing pulp amount. The optimal $\eta$ in machine direction was achieved as the mass ratio of butadiene-acrylonitrile rubber to para-phenylene terephthalamide pulp was 100:30. Excellent damping property was mainly attributed to the extremely high interfacial contact area which significantly improved the efficiency of energy dissipation of internal friction, interfacial sliding and dislocation motion between para-phenylene terephthalamide pulps and butadiene-acrylonitrile rubber chains. Since para-phenylene terephthalamide pulp modified damping materials offer a high $E^{\prime}$, excellent vibration damping properties, broad damping temperature and frequency ranges, it is ideal for free-damping structures which are widely utilized in industrial vibration and noise control applications.
\end{abstract}

\section{Keywords}

Para-phenylene terephthalamide pulp modified damping material, damping property, loss factors, storage modulus, loss modulus

\section{Introduction}

Damping polymer materials are commonly utilized for noise and vibration control in the particular industrial, transportation and defense equipment field as their high damping properties around the glass transition temperature. ${ }^{1,2}$ Free-damping, as one of the most simple and widely used damping structures, requires damping polymer material with a high loss modulus $\left(E^{\prime \prime}\right)$ on one hand, and on the other hand demands the glass transition temperature range of damping material to match the ambient temperature and resonance
'Department of Engineering Mechanics, School of Naval Architecture, Ocean \& Civil Engineering, Shanghai Jiaotong University, Minhang, Shanghai, People's Republic of China

${ }^{2}$ Key Laboratory of Microgravity, Institute of Mechanics, Chinese Academy of Sciences, Beijing, People's Republic of China

\section{Corresponding authors:}

Baihua Yuan, Department of Engineering Mechanics, School of Naval Architecture, Ocean \& Civil Engineering, Shanghai Jiaotong University, Minhang, Shanghai 201100, People's Republic of China. Email: jxaj@।63.com

Heng Jiang, Key Laboratory of Microgravity, Institute of Mechanics, Chinese Academy of Sciences, Beijing 100190, People's Republic of China. Email: hengjiang@imech.ac.cn 
frequency of the structure. However, apart from the advantages that damping polymer materials offer, they still bring some drawbacks as well. In fact, the pure polymer matrix is inappropriate for the practical application. The explanation for it is as follows: First and foremost, the glass transition temperature of the pure polymer matrix is usually lower or higher than ambient temperature. Second, the pure matrix does not have a satisfactory vibration damping property, as a result its $E^{\prime \prime}$ is far less than the modulus of the structure. Accordingly, it is necessary to explore new modified techniques for broadening the glass transition temperature range and increasing the $E^{\prime \prime}$ of the polymer matrix. ${ }^{3,4}$

One of the most commonly used measures to widen the temperature range of glass transition and to improve the $E^{\prime \prime}$ is to modify the matrix with sheet-like inorganic or metal powder fillers, such as mica powder, pottery clay, calcium carbonate, kaolin and lead powder, etc. ${ }^{5-9}$ However, the mechanical properties of inorganic particles or metal powders modified damping materials would decrease since the interface bonding strength between the fillers and polymer matrixes is relatively low. Recently, fibers modified damping materials have attracted much attention due to their high modulus, damping properties, mechanical strength and excellent thermal stability. Hajime et al. ${ }^{10}$ investigated the damping properties of thermoplastic-elastomer interleaved carbon fiber-reinforced epoxy composites and found that the arrangements and stiffness of the reinforcing carbon fiber in the laminates play a vital role in the loss factor of the composites. Ajayan et al. ${ }^{11}$ prepared carbon nanotube-reinforced polymer composites and revealed that the interfacial slippage between nanotubes and surrounding polymer chains could be exploited to inject structural damping efficiently into composite systems. However, carbon fiber and carbon nanotube are unsuitable for large-scale industrial applications due to their expensive cost and dispersion limitation in a polymer matrix. ${ }^{12}$

Para-phenylene terephthalamide (PPTA) pulp made from PPTA fibers has kept the merits of their precursors, such as high modulus, superior tensile property, good chemical and environmental resistance and excellent thermal property. ${ }^{13}$ Besides, PPTA pulp contains an abundance of curling and branching fibrils, which makes it has higher specific surface area and be dispersed uniformly in a matrix polymer compared to PPTA fibers. ${ }^{14}$ By virtue of their extraordinary performance, PPTA pulp has applications in a diversity of commercial fields, especially for the automobile industry. ${ }^{14}$ Nevertheless, PPTA pulp has been regarded as such reinforcing material that would weaken the hysteretic properties and energy loss fraction of the matrix polymer as that the loss tangent $(\operatorname{tg} \delta)$ of matrix polymer is decreased with the addition of the pulp. ${ }^{15,16}$ However, there is no literature on the damping properties of PPTA pulps modified damping materials.

In this study, the dynamic mechanical properties, differential scanning calorimetry (DSC), vibration damping properties, vulcanization property, tensile strengths as well as scanning electron microscopy (SEM) micrographs of the damping materials were investigated theoretically and experimentally. The modification mechanism of a PPTA pulp was explored by comparing the dynamic mechanical properties with aramid short-cut fiber, E-glass staple fiber and carbon fiber powder modified damping materials. The merits and demerits of the PPTA pulp modified damping material were discussed and compared with carbon nanotube-reinforced polymer composites and organohybrid-based damping material.

\section{Experimental}

\section{Materials}

Butadiene-acrylonitrile rubber (NBR) was supplied by Zeon Chemicals L.P. PPTA pulp (Kevlar Engineered Elastomer) was obtained from DuPont Corporation. Carbon black (N330) was supplied by Cabot Corporation. Mica powder (with the particle diameter of 40-mesh) was supplied by Lingshou Xingguang mica processing factory. Stearic acid was purchased from Hangzhou Oleochemicals Co., Ltd. Curing agent insoluble sulfur, curing activator $\mathrm{ZnO}$ (Nanometer Zinc Oxide), vulcanization accelerator $\mathrm{CZ}$ (N-cyclohexylbenzothiazole-2sulphenamide) and TMTD (Tetramethylthiuram disulfide) were supplied by Lanxess Energizing Chemistry Corporation. Steel plates with $1 \mathrm{~mm}$ thickness were obtained from Steel \& Iron Factory.

\section{Preparation of PPTA pulp modified damping materials and extensional damping beams}

Preparation of PPTA pulp modified damping materials. The samples investigated in this paper were compounded with different concentration of Kevlar Engineered Elastomer according to the recipe showed in Table 1. The equipment and procedures for preparation, mixing and vulcanization were in accordance with International Standard ISO 2393:2014(E). ${ }^{17}$

In order to obtain the identical degree of fiber dispersion and orientation of each sample, it was important to keep the process parameters of each sample strictly consistent. The main process parameters were as follows: (1) The internal mixer rotor speed and the mixing time were $10 \mathrm{r} / \mathrm{min}$ and $10 \mathrm{~min}$, respectively. (2) The clearance between rolls of mixing mill was $0.5 \mathrm{~mm}$. (3) The vulcanization process was performed by compression molding process at $160^{\circ} \mathrm{C}$ for $10 \mathrm{~min}$ under $10 \mathrm{MPa}$ pressure. 
Figure 1 shows the Photograph and SEM of the PPTA pulp and modified damping material. As shown in Figure 1, PPTA pulp contains an abundance of curling and branching fibrils, which makes it has

Table I. Composition of Kevlar Engineered Elastomer filled NBR systems.

\begin{tabular}{|c|c|c|c|c|c|c|}
\hline \multirow{2}{*}{$\begin{array}{l}\text { Ingredients } \\
\text { (phr) }\end{array}$} & \multicolumn{6}{|c|}{ Formula no. } \\
\hline & KO & $\mathrm{KI}$ & $\mathrm{K} 2$ & $\mathrm{~K} 3$ & K4 & K5 \\
\hline NBR & 100 & 100 & 100 & 100 & 100 & 100 \\
\hline $\mathrm{ZnO}$ & 5 & 5 & 5 & 5 & 5 & 5 \\
\hline Stearic acid & 2 & 2 & 2 & 2 & 2 & 2 \\
\hline $\begin{array}{l}\text { Carbon } \\
\text { black N330 }\end{array}$ & 20 & 20 & 20 & 20 & 20 & 20 \\
\hline $\begin{array}{l}\text { Kevlar } \\
\text { Engineered } \\
\text { Elastomer }\end{array}$ & 0 & 10 & 20 & 30 & 40 & 50 \\
\hline Mica powder & 50 & 50 & 50 & 50 & 50 & 50 \\
\hline Insoluble sulfur & 1.5 & 1.5 & 1.5 & 1.5 & 1.5 & 1.5 \\
\hline$C Z$ & 1.5 & 1.5 & 1.5 & 1.5 & 1.5 & 1.5 \\
\hline TMTD & 0.5 & 0.5 & 0.5 & 0.5 & 0.5 & 0.5 \\
\hline
\end{tabular}

NBR: butadiene-acrylonitrile rubber; TMTD: tetramethylthiuram disulfide. higher specific surface area and be dispersed uniformly in a matrix polymer.

Preparation of extensional damping beams. Before the preparations of extensional damping beams, steel beams $(205 \mathrm{~mm} \times 10 \mathrm{~mm} \times 1 \mathrm{~mm})$ and damping materials $(180 \mathrm{~mm} \times 10 \mathrm{~mm} \times 2 \mathrm{~mm})$ were sanded to improve the adhesive attraction between damping materials and steel beams. The steel beams were coated with damping materials by epoxy adhesives and vulcanized at room temperature. Six specimens were prepared for each sample recipe; three of them were coated with the damping materials at which the length directions were parallel to the fiber orientation direction, and the other three were perpendicular to the fiber orientation direction.

\section{Measurements}

Dynamic mechanical analysis. Dynamic mechanical analysis (DMA) was carried out on a DMA Q800 analyzer (TA Instruments, America) with single cantilever mode over a temperature range from $-40^{\circ} \mathrm{C}-+60^{\circ} \mathrm{C}$ at a heating rate of $3^{\circ} \mathrm{C}$ per minute at $10 \mathrm{~Hz}$. Three rectangular specimens $(17 \mathrm{~mm} \times 11 \mathrm{~mm} \times 2 \mathrm{~mm})$ were tested for three typical recipes $\mathrm{K} 0, \mathrm{~K} 1$ and $\mathrm{K} 3$, in which the weight contents of Kevlar Engineered Elastomer were $0 \mathrm{phr}, 10 \mathrm{phr}$ and $30 \mathrm{phr}$, respectively.

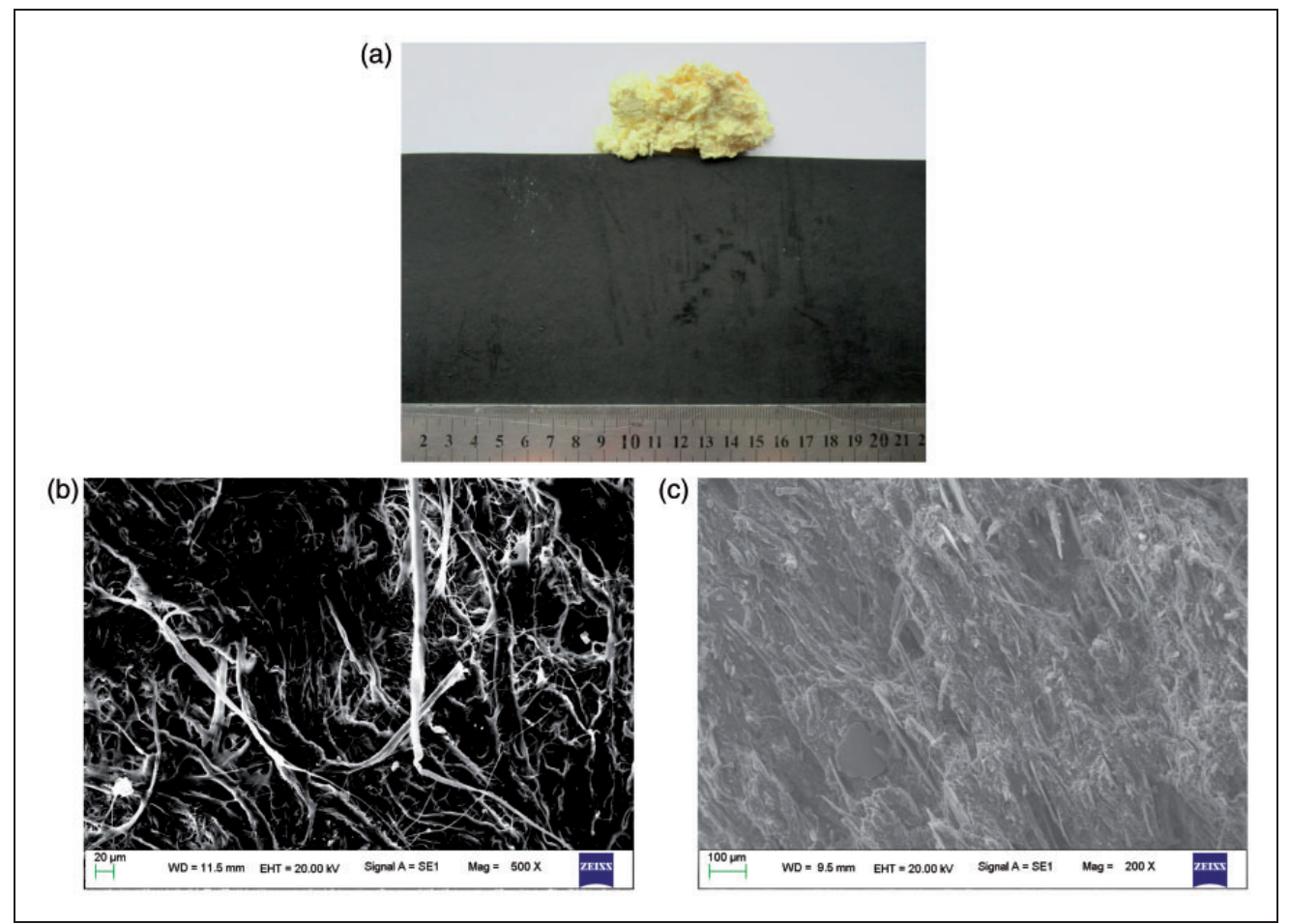

Figure I. Photograph and SEM of the PPTA pulp and modified damping material. (a) Photograph of the PPTA pulp and modified damping material, (b) SEM of the PPTA pulp and (c) SEM of the modified damping material. 
Differential scanning calorimetry. DSC tests were performed on a DSC apparatus of Mettler Toledo (model: DSC1) (Produced by Mettler-Toledo, Switzerland) at a heating rate of $10^{\circ} \mathrm{C}$ per minute from $-80^{\circ} \mathrm{C}$ to $180^{\circ} \mathrm{C}$ under a nitrogen atmosphere. The glass transition temperature $\left(T_{g}\right)$ values have been deduced from the inflection point of the DSC curves on the second heating run.

The vibration damping properties of extensional damping beams. The vibration damping properties characterized by the modal loss factor $(\eta)$ were measured by cantilever method according to ASTM E756-2010 ${ }^{18}$ with a set of apparatus, which include a noncontacting exciter transducer type DH450020 (Jiangsu Donghua Testing Technology Co., Ltd, China), a power amplifier type DH1301, a laser vibrometers and data management system type PSV-500 (Polytec Corporation, Germany). The samples were steel beams coated with damping materials as mentioned above. The $\eta$ was determined from the sharpness of the response curves $\eta=\Delta f_{n} / f_{n}$, in which $f_{n}$ is the resonance frequency of resonance mode $n$, and $\Delta f_{n}$ is the bandwidth $3 \mathrm{~dB}$ down from the $n$th resonance peak. ${ }^{19}$

Vulcanization property. Vulcanization property of the damping material was carried out on a rotorless cure meters (type GT-M2000A, GOTECH Testing Machines Inc.) according to ASTM D5289-2007a. ${ }^{20}$ The test temperature was $160^{\circ} \mathrm{C}$, and the amplitude of the oscillation was $\pm 0.5^{\circ}$.

Tensile strength measurement. Tensile properties were performed using a computer controlled electronic universal testing machine RGM-3030 (Shenzhen Reger Instrument co., Ltd, China), according to ASTM D412-06a (Reapproved 2013). ${ }^{21}$

\section{Results and discussion}

\section{Dynamic mechanical analysis}

Figures 2 and 3 show the temperature dependences of $E^{\prime}$, $E^{\prime \prime}$ and $\operatorname{tg} \delta$ in the machine direction when the content of PPTA pulps was $0 \mathrm{phr}, 10 \mathrm{phr}$ and $30 \mathrm{phr}$, respectively. The $\operatorname{tg} \delta$ is the $E^{\prime \prime}$ to $E^{\prime}$ ratio $\left(\operatorname{tg} \delta=E^{\prime \prime} / E^{\prime}\right)$. The peak of the $E^{\prime \prime}$ curve corresponds to the glass transition temperature $\left(T_{g}\right)$ of the composite. The $E^{\prime}$ and $E^{\prime \prime}$ were significantly improved with increasing pulp content while the $T_{g}$ was nearly unaffected, but the temperature range of glass-rubber transition region was widened outstandingly. It indicates that the service temperature and frequency limits of modified damping materials were broadened accordingly.

There are two mechanisms accounting for this obvious improvement of $E^{\prime}$ in machine direction. First, the interface bonding strength of PPTA pulp and NBR matrix was greatly reinforced owing to the large number of hydrogen bonding formed from the amino and carboxyl groups on the chain of PPTA, and the cyano on the chain of NBR. Also, the interface bonding strength could be further strengthened for the high specific surface area of pulp. This will result in an efficient transformation of stress from the matrix to PPTA fibers. Second, since the elastic modulus of PPTA is much higher than the modulus of NBR matrix, this is analogous to introduce and distribute a large amount

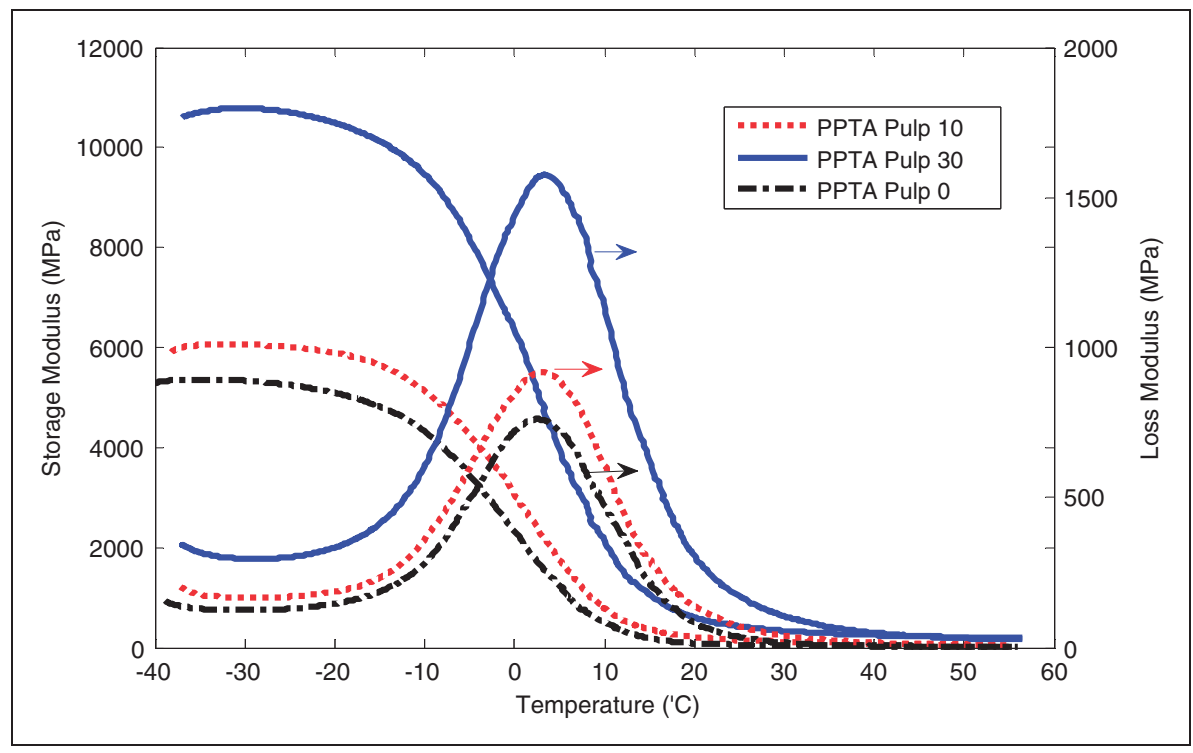

Figure 2. The temperature dependency of the modulus in machine direction. PPTA: para-phenylene terephthalamide. 


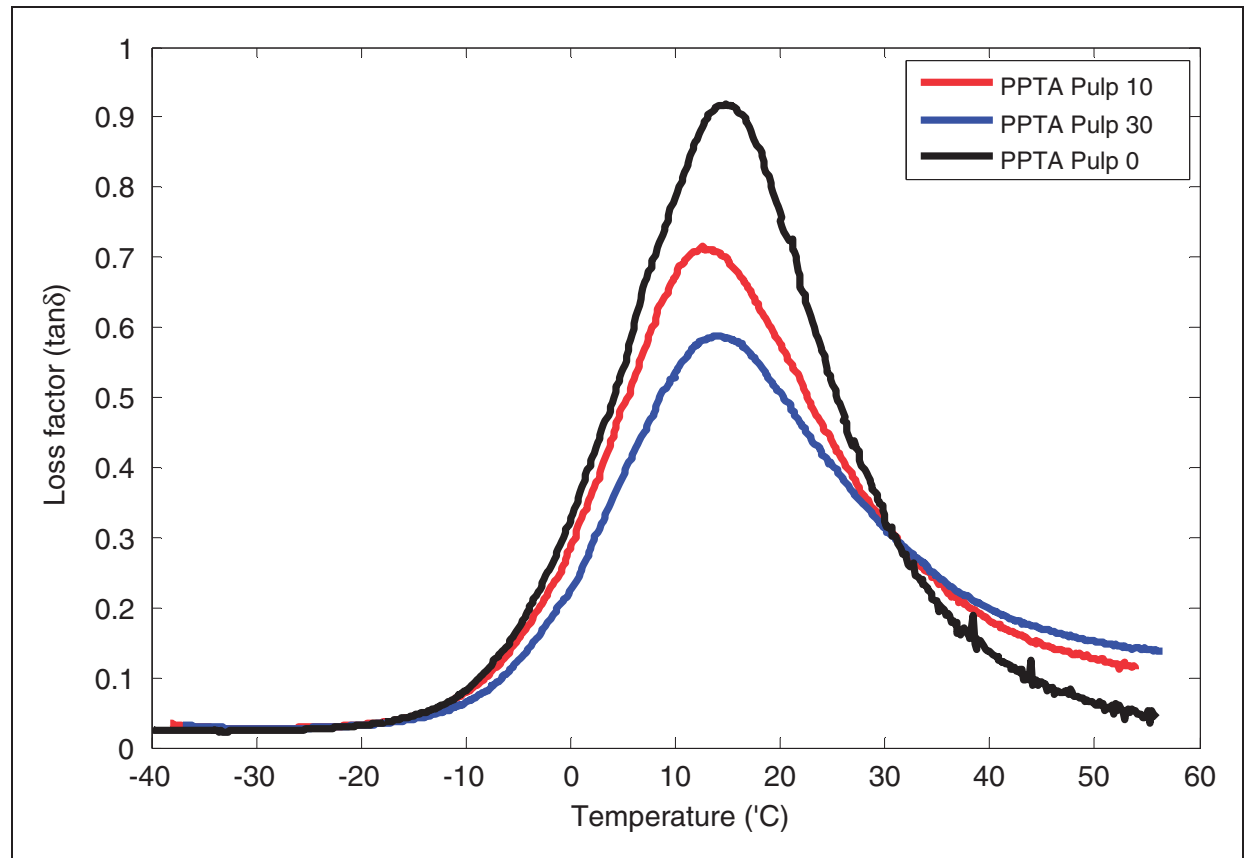

Figure 3. The temperature dependency of the $\operatorname{tg} \delta$ in machine direction.

PPTA: para-phenylene terephthalamide.

of spring with higher elastic modulus in the NBR matrix in parallel, thereby the elastic modulus of the composite system was improved outstandingly. Obviously, the more PPTA pulp is incorporated, the higher $E^{\prime}$ of damping material will be.

There are two main mechanisms on how to increase the $E^{\prime \prime}$ of damping material in the machine direction. First, when PPTA pulp was incorporated, the free volume portion of NBR matrix was filled partly by the chain of PPTA, which enhanced the degree and number of entanglements between molecular chains of the matrix, the viscosity of the composite system and the internal friction between the PPTA and polymer chains as well as friction between pulps. As shown in Figure 2, the increase in viscosity of damping material could be verified by the fact that the peaks of $E^{\prime \prime}$ curve shifted to a higher temperature with increasing pulp content. In additional, the interfacial contact area between the fiber and the matrix was substantially increased for the greatly high specific surface area and the large number of ultra-fine fibrils on pulp surface. This would improve the level of internal friction, slip and dislocation motion between the PPTA and polymer chains as well as friction between pulps ${ }^{22}$ and thereby increased the rate of dissipating energy.

In order to verify the key role played by the greatly high specific surface area and the large number of ultrafine fibrils on pulp surface in improving the $E^{\prime}$ and $E^{\prime \prime}$, the dynamic mechanical properties of PPTA pulp modified damping materials were studied and were compared with aramid short-cut fiber (DuPont Corporation, length 3-6 mm), E-glass staple fiber (Jushi Group Co., Ltd., length 3-6 mm) and carbon fiber powder (Toray Corporation, particle size 300 mesh) modified damping materials. Figure 4 shows the dynamic mechanical properties of four types of fibers modified damping materials in the machine direction. The results showed that, compared to the other three types of fibers, PPTA pulp modified damping materials exhibited the best damping performance and the highest modulus. There are two main causes of this phenomenon. First and foremost, the specific surface area of PPTA pulp is significantly higher than the other fibers, nearly 10 times larger than aramid fiber and glass staple fibers, in addition, the surface polar groups content is 10 times more than aramid fiber, therefore, there are larger interfacial contact area and stronger interfacial bonding strength between PPTA pulp and matrix interfacial area. Second, PPTA pulps have two distinct advantages of good dispersion properties in the polymer matrix and fine toughness properties of main chains compared to aramid, short glass and carbon fibers. Those advantages could enable the pulps to resist the decrease of the fiber aspect ratio in high shear mixing processes, which has been a difficulty for short glass fiber and carbon fiber to solve.

As shown in Figure 4, within the glass transition temperature range $\left(-10^{\circ} \mathrm{C}-30^{\circ} \mathrm{C}\right)$, increasing pulp content has reduced the $t g \delta$ of PPTA pulp modified damping material. This phenomenon suggested that the increase rate of $E^{\prime}$ was higher than that of the $E^{\prime \prime}$ with 


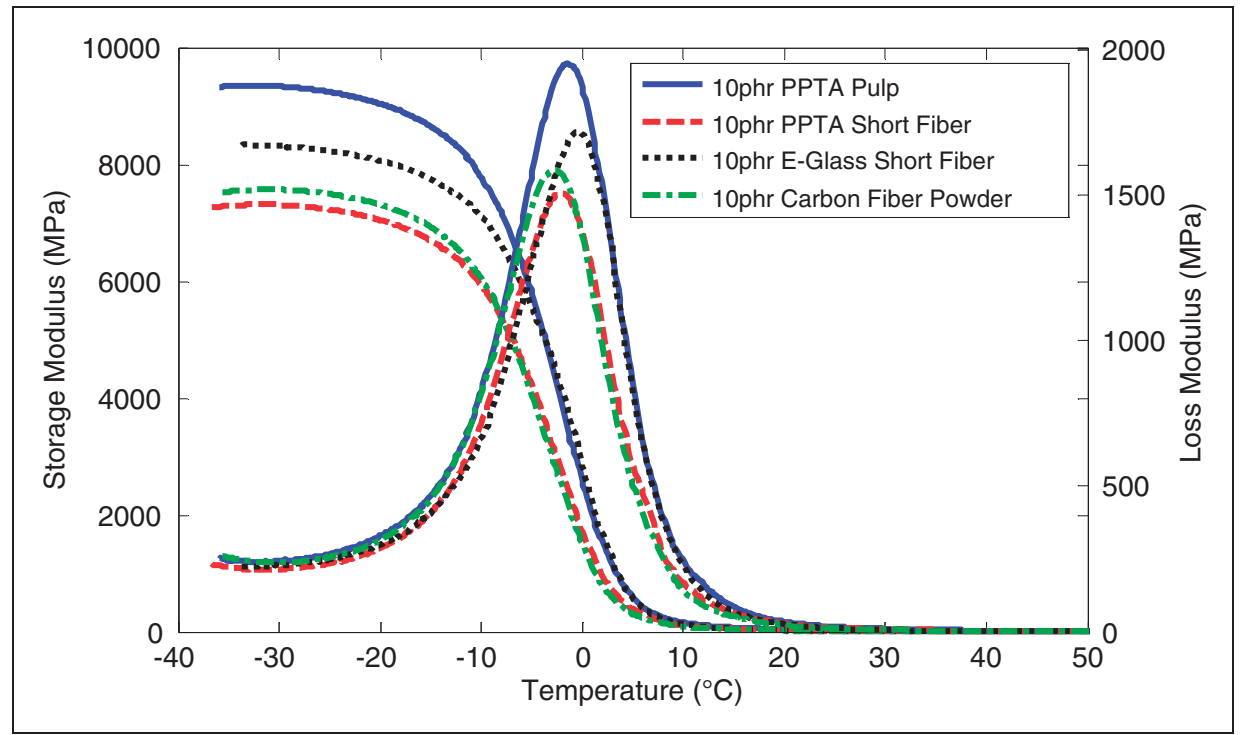

Figure 4. DMA of four kinds of fibers modified damping material in machine direction. PPTA: para-phenylene terephthalamide.

increasing pulp content obtained from the equation of $\operatorname{tg} \delta=E^{\prime \prime} / E^{\prime}$. In contrast, a different trend was observed within a rubber-elastic plateau region; in fact, the $\operatorname{tg} \delta$ of damping material was increased with increasing pulp content. Also, this enhancement was demonstrated to be lower in $E^{\prime}$ in comparison with $E^{\prime \prime}$ with increasing pulp amount. The essential reason in this trend mentioned above was the temperature dependency of the molecular motion of the polymer matrix. ${ }^{23}$ Within the glass transition temperature range, polymer segments get enough energy and space to begin to move, but the internal friction between segments is large. Though increasing temperature led to a decrease in the interfacial bonding strength of PPTA pulp and NBR matrix, it can still transfer and distribute effectively stress from matrix to PPTA fiber. Meanwhile, as the elastic modulus of PPTA is about 1000 times higher than that of in matrix, the increase rate is higher in $E^{\prime}$ than in $E^{\prime \prime}$, which results in the decrease of the $\operatorname{tg} \delta$. Within a rubber-elastic plateau region, since polymer segments can move unrestrictedly, the interfacial bonding strength of PPTA pulp and NBR matrix was decreased outstandingly. It has also reduced sharply the modulus of polymer matrix to less than $10 \mathrm{MPa}$. Moreover, the role of PPTA pulp in improving the $E^{\prime}$ became very difficult. On the contrary, the molecular chain of PPTA pulp was still kept rigid. Thus, the internal friction between PPTA pulp and polymer matrix was sharply dropped. However, the internal friction between PPTA pulps was increased with increasing pulp content. In addition, due to the thermal motions of the matrix segments, the hydrogen bonds between the PPTA pulp and polymer matrix were dissociated and consociated alternately. The energy dissipation due to dissociation of the intermolecular hydrogen-bond network is larger than the one which is associated with the general friction between polymer chains. ${ }^{24}$ Accordingly, the increase rate of $E^{\prime}$ is no more than the $E^{\prime \prime}$ with increasing pulp content, which resulted in the increase of the $\operatorname{tg} \delta$.

According to Figure 5, the improvements of $E^{\prime}$ and $E^{\prime \prime}$ in machine direction were more pronounced than that of in cross-machine direction. Modular anisotropy, as expected is a common of fiber-reinforced composites and is a consequence of fiber orientation. Since, on the one hand, the length-diameter aspect ratio of PPTA is about 100, and on the other hand, PPTA is a kind of rigid fiber, PPTA fibers are much easier to arrange along the rolling direction in high shear processing on a roll mill. The smaller clearance between rolls of mixing mill, the higher the degree of fiber orientation will be; this phenomenon is also known as "rolling effect." ${ }^{23}$ Accordingly, the stress could be effectively transferred from matrix to PPTA fiber in the machine direction, but not be in the cross-machine direction. In fact, the higher the degree of fiber orientation is, the higher the degree of anisotropy is Li. ${ }^{25}$ There are two main measures to eliminate or reduce anisotropy, one is enlarging the clearance between rolls of mixing mill in mixing process, and another one is making the compound be cross-laminated in vulcanization processing.

\section{Differential scanning calorimetry}

Figure 6 shows the influence of pulp content on DSC of the PPTA pulp modified damping material. The extremely mutable sites of the DSC curve correspond to the glass transition temperature $\left(T_{g}\right)$ of the composite. As can be seen, the incorporation of PPTA pulp does not 


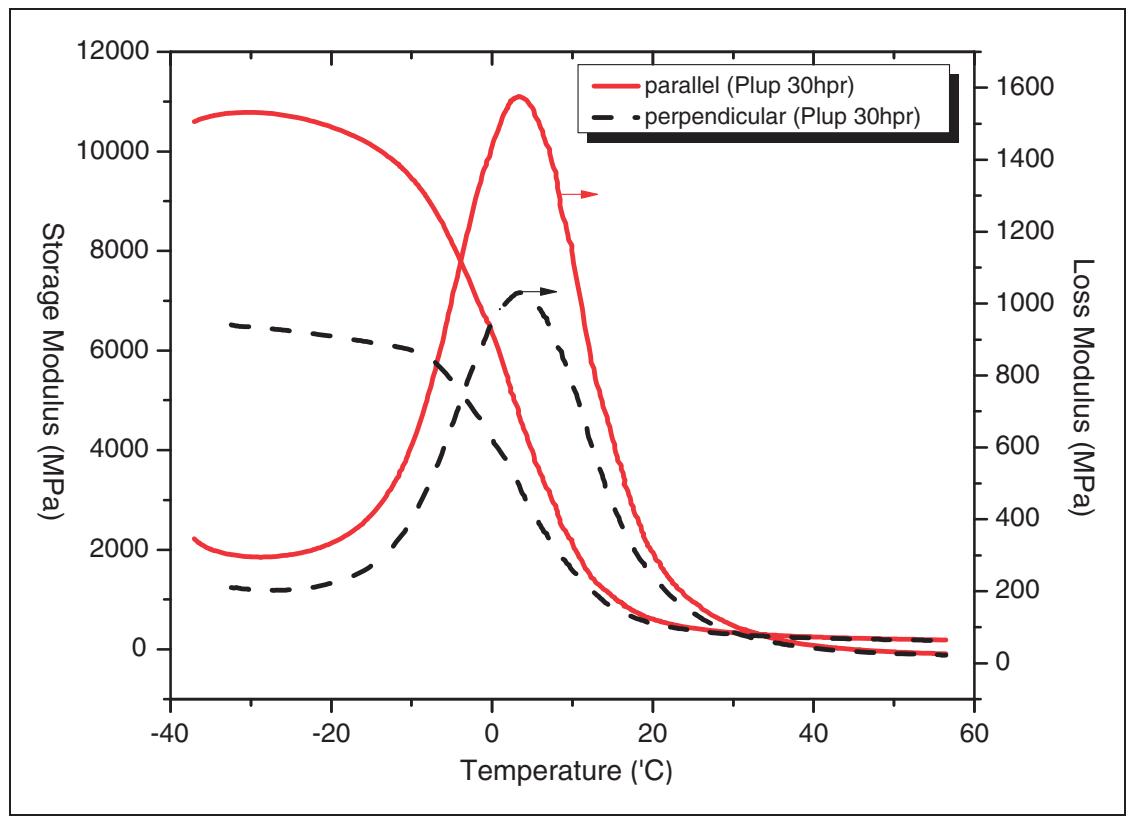

Figure 5. DMA both in machine and cross-machine direction when pulp is $30 \mathrm{phr}$.

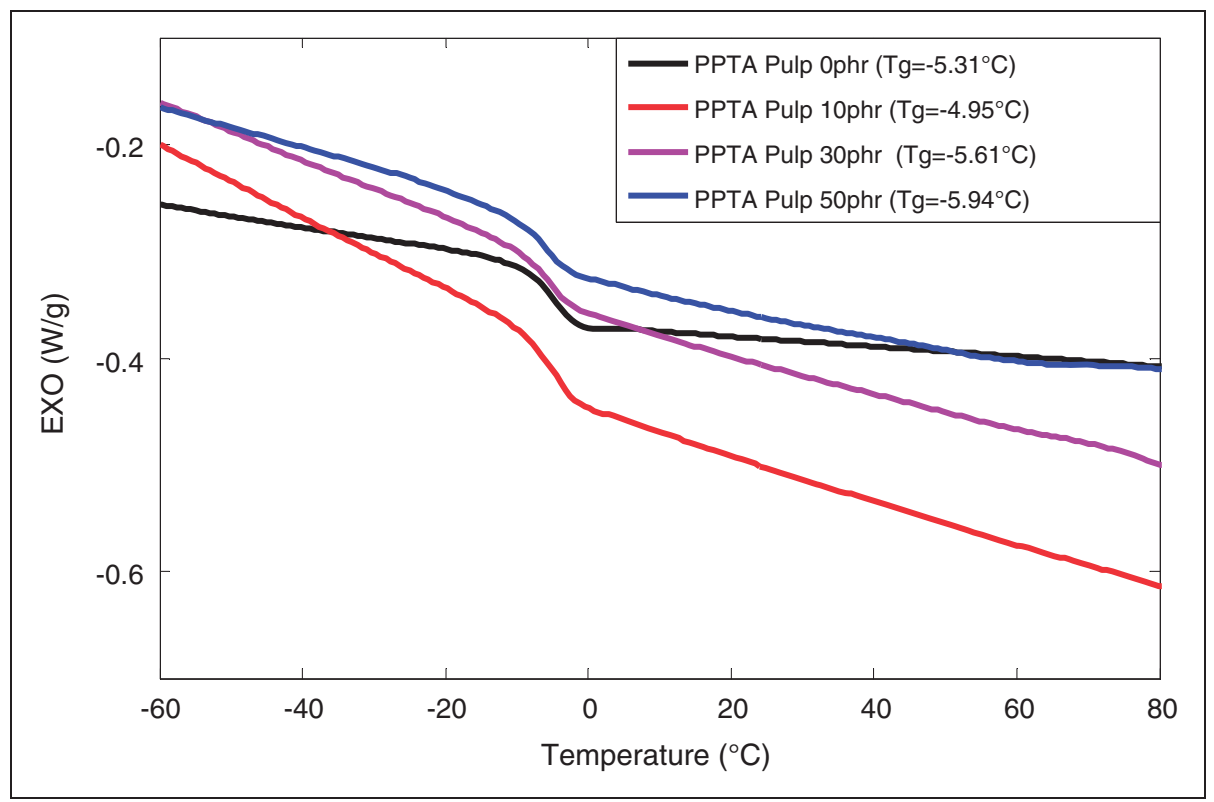

Figure 6. DSC of the pulp modified damping material.

PPTA: para-phenylene terephthalamide.

affect the $T_{g}$, which demonstrates that the blends of PPTA pulp and polymer matrix are thermodynamically incompatible.

\section{The vibration damping properties of extensional damping beams}

Figure 7 shows the frequency dependence of the $\eta$ of extensional damping beams in the machine direction. The $\eta$ of the second, third and fourth modes was increased substantially in first, and then became stable with increasing pulp content. The optimal value of $\eta$ was achieved as the mass ratio of NBR and PPTA pulp was 100:30. However, the $\eta$ of the first mode was nearly unaffected by the incorporation of PPTA pulp because the wavelength of low frequency is far longer than the thickness of damping coating.

As shown in Figures 3 and 7, increasing pulp content decreased the $\operatorname{tg} \delta$ of damping material, when the 


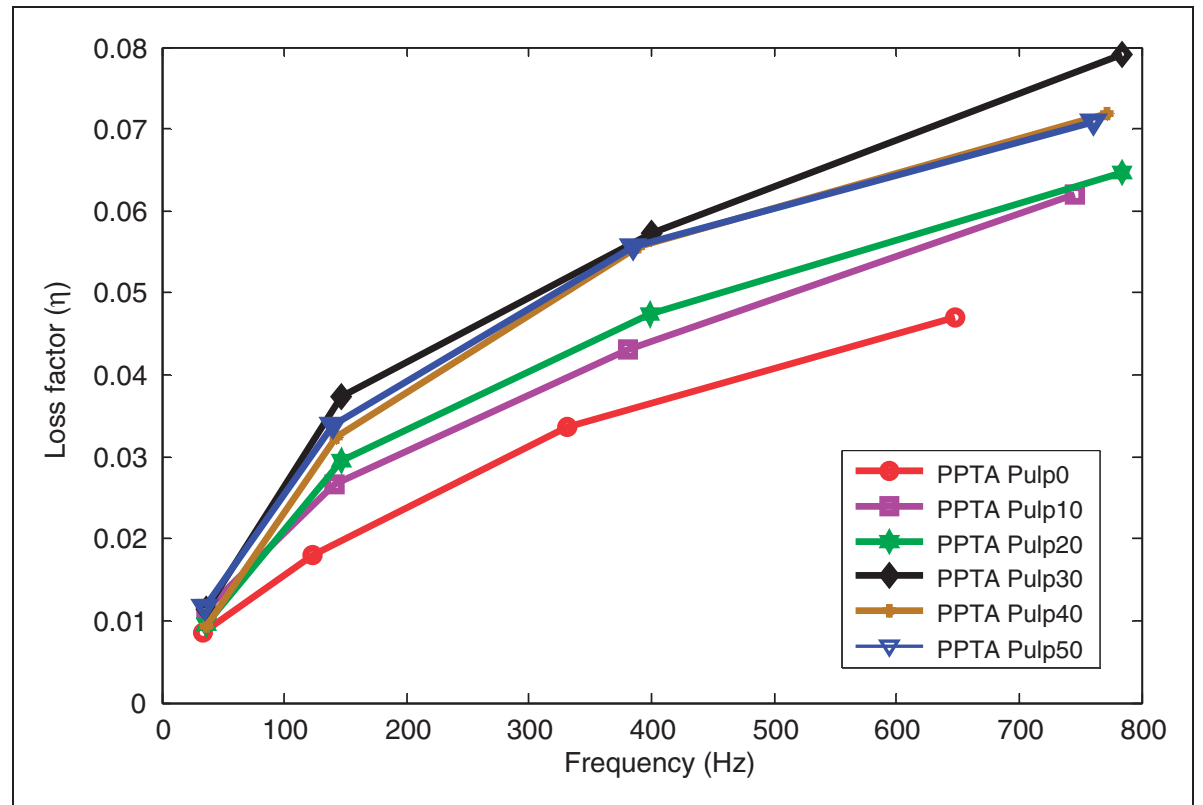

Figure 7. The $\eta$ of extensional damping beams in machine direction.

PPTA: para-phenylene terephthalamide.

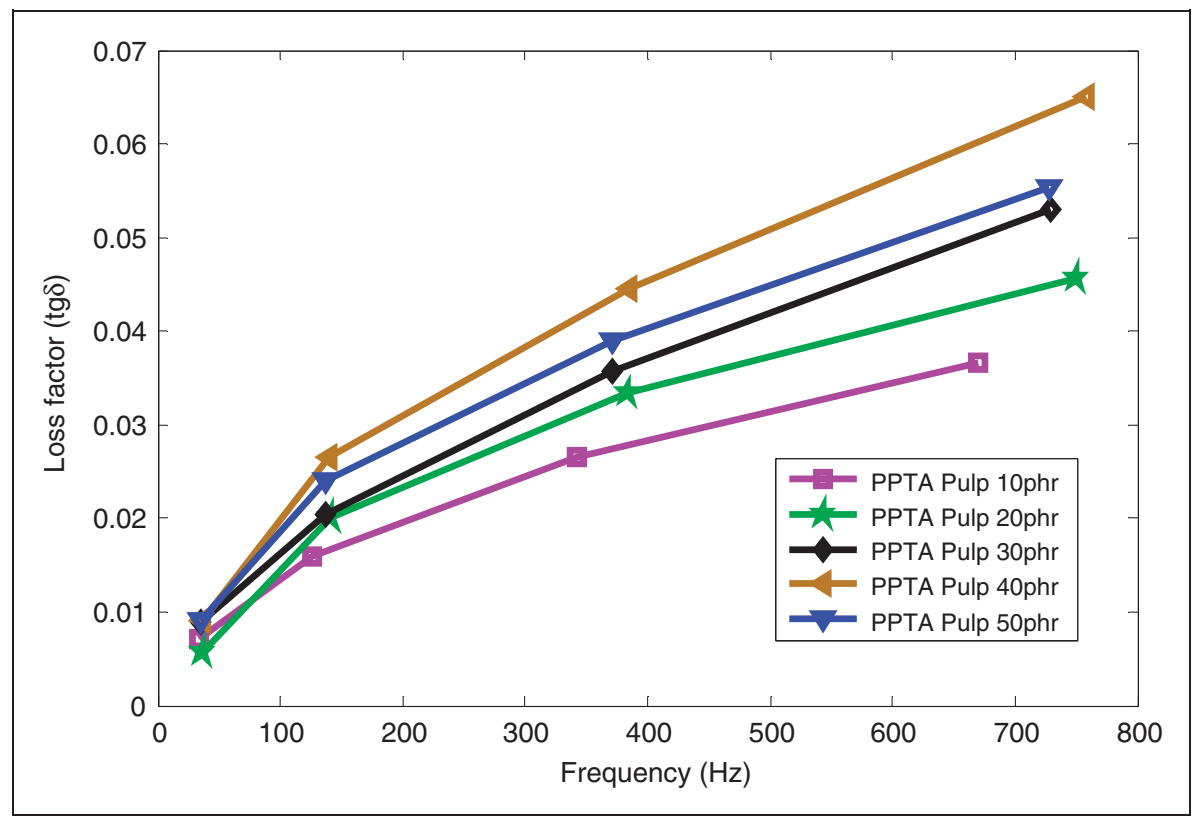

Figure 8. The $\eta$ of extensional damping beams in cross-machine direction.

PPTA: para-phenylene terephthalamide.

content of PPTA was no more than $30 \mathrm{phr}$; in contrast, the $\eta$ of extensional damping beams was improved outstandingly. According to the equation (1), ${ }^{26}$ the $\eta$ of extensional damping beams is proportional to the $E^{\prime \prime}$ of damping coating, inversely proportional to the bending stiffness $(B)$ of the composite beam, and unaffected by the $\operatorname{tg} \delta$ of damping material. The contribution to
$B$ made by the $E^{\prime}$ of the damping material can be negligible since the $E^{\prime}\left(\approx 10^{9} \mathrm{~Pa}\right)$ is far less than the modulus of the base beam $\left(E_{1}=2.1 \times 10^{11} \mathrm{~Pa}\right)$

$$
\eta=\frac{E^{\prime \prime} H_{2} a^{2}}{B}=\frac{E^{\prime \prime} H_{2} a^{2}}{E_{1} H_{1}^{3} / 12+E^{\prime} H_{2} a^{2}} \approx \frac{E^{\prime \prime} H_{2} a^{2}}{E_{1} H_{1}^{3} / 12}
$$


Table 2. The vulcanization property of the pulp modified damping material.

\begin{tabular}{|c|c|c|c|c|c|c|}
\hline \multirow{2}{*}{$\begin{array}{l}\text { Test } \\
\text { parameter }\end{array}$} & \multicolumn{6}{|c|}{ 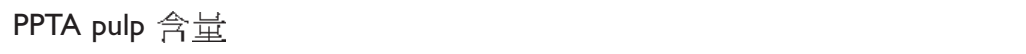 } \\
\hline & $0 \mathrm{phr}$ & $10 \mathrm{phr}$ & $20 \mathrm{phr}$ & $30 \mathrm{phr}$ & $40 \mathrm{phr}$ & $50 \mathrm{phr}$ \\
\hline$t_{10}(\mathrm{~m}: \mathrm{s})$ & I:03 & $\mathrm{I}: 04$ & $\mathrm{I}: 0 \mathrm{I}$ & $|: 0|$ & $|: 0|$ & $\mathrm{I}: 02$ \\
\hline$t_{90}(\mathrm{~m}: \mathrm{s})$ & $2: 32$ & $2: 30$ & $2: 34$ & $2: 33$ & $2: 26$ & $2: 35$ \\
\hline$M_{L}(\mathrm{dN}-\mathrm{m})$ & 0.40 & 0.59 & 0.91 & 1.19 & 1.35 & 1.76 \\
\hline$M_{H}(\mathrm{dN}-\mathrm{m})$ & 8.05 & 9.41 & 11.11 & 11.64 & 11.90 & 12.49 \\
\hline
\end{tabular}

PPTA: para-phenylene terephthalamide.

where $H_{1}$ and $H_{2}$ represent the thickness of the steel plate and damping material, respectively. And $a$ denotes the distance from the neutral fiber to the center-line of the damping material.

When the content of PPTA was more than $30 \mathrm{phr}$, the $E^{\prime}$ and $E^{\prime \prime}$ of modified damping materials were no longer affected by increasing pulp amount. This is due to the fact that the modulus of damping materials approaches to the modulus of PPTA. Accordingly, the $\eta$ of extensional damping beams was also no longer increased continuously (see equation (1)).

Figure 8 shows the frequency dependence of the $\eta$ of extensional damping beams in the cross-machine direction. The effects of the contents of PPTA pulps on damping properties of extensional damping structure in cross-machine direction were substantially close to that in the machine direction. However, when the content of PPTA pulps was $40 \mathrm{phr}$, the $\eta$ of all second, third and fourth modes in cross-machine direction reached their maximum values, while in the machine direction the optimal value of $\eta$ was observed when the amounts of PPTA pulps were $30 \mathrm{phr}$. The difference mainly came from the processing of samples, when the rubber compound was calendered to a thin gauge on a roll mill, there were some fibers arranged perpendicular to the rolling direction since the thickness of the thin gauge was several ten times more than the diameter of PPTA, which resulted in the improvements of $E^{\prime}$ and $E^{\prime \prime}$ in cross-machine direction. Figures 7 and 8 revealed the fact that the improvements in loss factors in the machine direction were obviously more than that of in cross-machine direction. When PPTA pulps were incorporated, the conclusions could be also applied to the improvements of $E^{\prime}$ and $E^{\prime \prime}$ as shown in Figure 5.

\section{Vulcanization property}

Table 2 shows the influence of pulp content on the vulcanization property of the PPTA pulp modified damping material. As can be seen, the incorporation of PPTA pulp does not affect the scorch time $\left(t_{10}\right)$ and the cure time $\left(t_{90}\right)$ of the vulcanizable compound. However, the minimum torque $\left(M_{L}\right)$ and the maximum

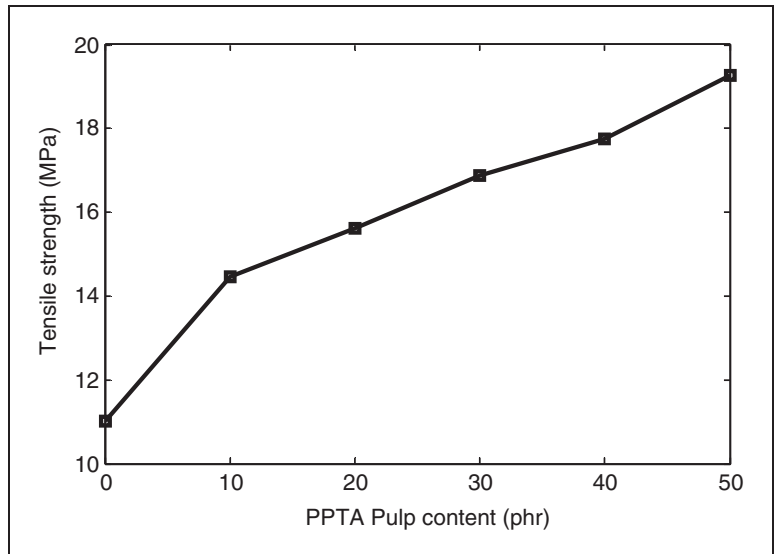

Figure 9. The tensile strength of PPTA pulp-reinforced composites in machine direction.

PPTA: para-phenylene terephthalamide.

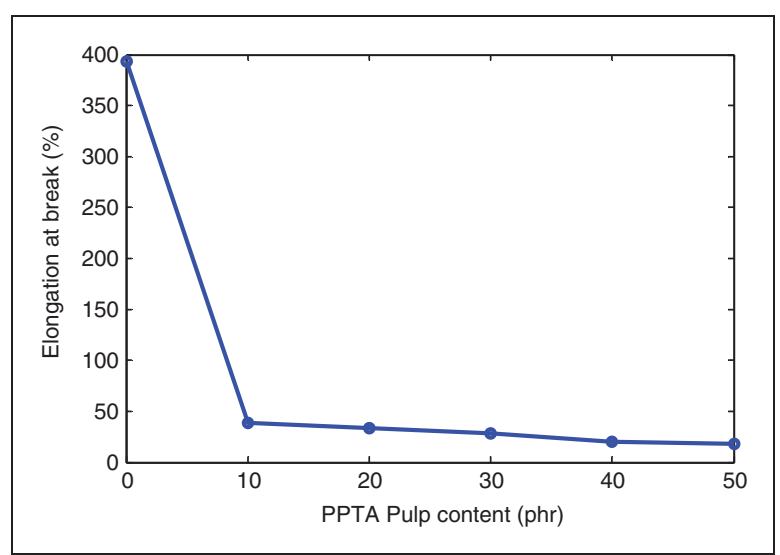

Figure 10. The elongation at break of PPTA pulp-reinforced composites in machine direction.

PPTA: para-phenylene terephthalamide.

torque $\left(M_{H}\right)$ of the compound are all increased significantly with increasing pulp content, which furtherly evidenced that the modulus of pulp modified damping material would be improved obviously as the pulp incorporated. 


\section{Tensile strength measurement}

As shown in Figures 9 and 10, the tensile strength of damping material filled with PPTA pulp in the machine direction increased significantly, and also the elongation at break was decreased outstandingly with increasing pulp content. The mechanism of reinforcing the damping material was the same as the mechanism of improving the modulus as mentioned before. The fractured surface morphologies of tensile samples for the PPTA pulp modified composites were shown in Figure 11. It could be seen that the main fracture mechanism in pulp-reinforced damping materials was fiber pull-out or fracture.
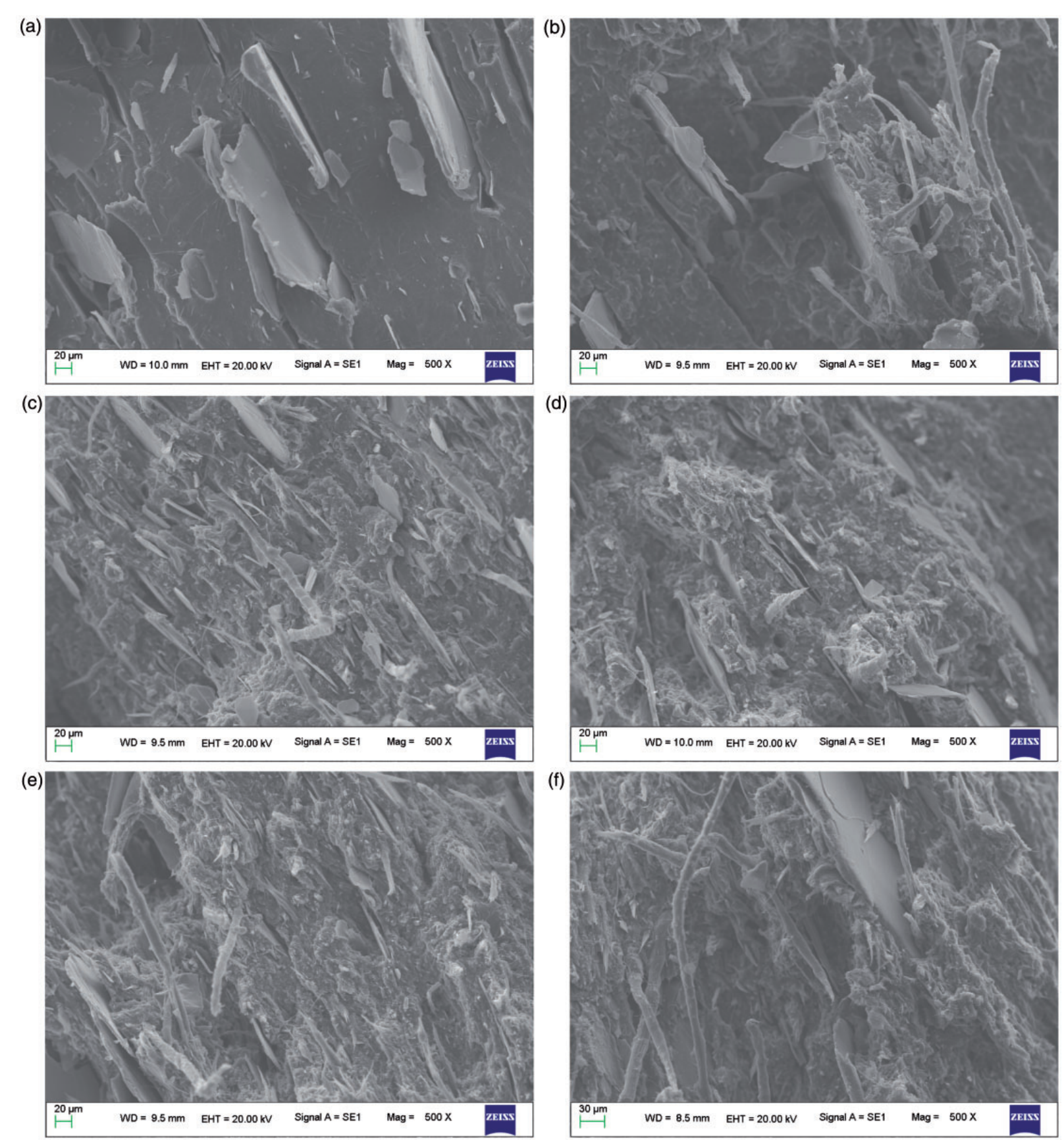

Figure II. SEM micrographs of the fractured surface in machine direction (magnified 500 times). (a) Pulp 0 phr, (b) Pulp I0 phr, (c) Pulp 20 phr, (d) Pulp 30 phr, (e) Pulp 40 phr and (f) Pulp 50 phr. 
Table 3. Tensile properties in both machine and cross-machine direction when pulp is 20 phr.

\begin{tabular}{lll}
\hline Fiber orientation & $\begin{array}{l}\text { Tensile } \\
\text { strength } \\
(\mathrm{MPa})\end{array}$ & $\begin{array}{l}\text { Elongation } \\
\text { at break (\%) }\end{array}$ \\
\hline Machine direction & 15.61 & 33.63 \\
Cross-machine direction & 11.95 & 52.32 \\
\hline
\end{tabular}

Compared to inorganic filler-reinforced polymer, the outstanding advantage of PPTA pulp-reinforced polymer was the characteristic that the density was nearly unaffected by the concentration of PPTA pulps used in the compound.

As can be seen from Table 3, the tensile property anisotropy is distinct in PPTA pulp modified composites, as traditional fibers. As it was previously mentioned, this phenomenon associated with the fiber orientation.

\section{Comparison of the experimental results with other reported modification methods}

In order to explore the characteristics and engineering applications of PPTA pulp modified damping material, the merits and demerits of the PPTA pulp modified damping material were discussed and compared with carbon nanotube-reinforced polymer composites ${ }^{11,27}$ and organohybrid-based damping material, ${ }^{28-32}$ which have been extensively researched.

Ajayan et al. ${ }^{11}$ and Liu et al. ${ }^{27}$ shown that carbon nanotube-reinforced polymer composites have very high stiffness and mechanical damping, which were resulted from the extremely large interfacial contact area and the interfacial slippage between nanotubes and polymer matrix. Compared to PPTA pulp modified damping materials, carbon nanotube-reinforced composites exhibited the better damping performance and modulus. However, several challenges still remain for the synthesis and application of the nanotube-polymer composites. First, due to van der waals interactions, it is very challenging to prevent the agglomeration of carbon nanotubes. Secondly, due to their expensive cost, carbon nanotube is unsuitable for large-scale industrial applications.

Recently, $\mathrm{Wu}^{28-31}$ has discovered that the addition of hindered amine and hindered phenol small molecular substances into an immiscible acrylate rubber (ACM) and chlorinated polyethylene (CPE) resulted in a remarkable enhancement of the damping properties, which was named "organohybrid-based damping material" and was regarded as created a new method and concept of excellent damping material. ${ }^{32}$ This damping material has high $\operatorname{tg} \delta$ and designable $T_{g}$ due to the formation of intermolecular hydrogen bonds between small molecular substance and polymer matrix; however, the $E^{\prime \prime}$ of the damping material has not been improved as the small molecular substance incorporated. Therefore, it is very perfect for constrained-layer damping structure in which the $\eta$ is proportional to the $\operatorname{tg} \delta$ of damping coating.

\section{Conclusions}

In this study, a series of tests were carried out in order to determine the dynamic mechanical properties, vibration damping properties, vulcanization property and tensile strengths of the damping materials in both machine and cross-machine direction. Based on the obtained results, the following conclusions can be drawn:

1. The $E^{\prime}, E^{\prime \prime}$, tensile strength and damping properties of NBR matrix could be significantly improved through using PPTA pulp into the matrix, which does not take any interference to the glass transition temperature and the vulcanization property.

2. The improvements in the machine direction were significantly greater than that of in the cross-machine direction.

3. Compared to aramid short-cut fiber, E-glass staple fiber and carbon fiber powder modified damping materials, PPTA pulp modified damping materials exhibited the best damping performance and the highest modulus. The increase of the rate of dissipating energy could be attributed to the extremely large interfacial contact area of PPTA pulp, which led to a great deal of additional friction, interfacial sliding and dislocation motion into the polymer chains when pulp was incorporated. In addition, the significant improvement in modulus could be credited with the strong interface bonding strength resulted from the hydrogen-bonding formed between the polar groups of pulp and the polymer chains.

Compared to carbon nanotube-reinforced polymer composites and organohybrid-based damping material, pulp modified damping materials are very perfect for free-damping structures which are widely utilized in industrial vibration and noise control applications due to their high modulus, vibration damping properties, broad damping temperature and frequency range.

\section{Declaration of Conflicting Interests}

The author(s) declared no potential conflicts of interest with respect to the research, authorship, and/or publication of this article.

\section{Funding}

The author(s) received no financial support for the research, authorship, and/or publication of this article. 


\section{References}

1. Ahn SK, Jeon E, Park J, et al. Investigation of damping in the polymer concrete sleeper for use in reduction of rolling noise from railway. $J$ Acoust Soc Am 2014; 136 : 2209-2210.

2. Mcneely M. Vibration damping device. J Acoust Soc Am 2015; 91: 3083-3083.

3. Muthusamy S, Wang S and Chung DDL. Unprecedented vibration damping with high values of loss modulus and loss tangent, exhibited by cement-matrix graphite network composite. Carbon 2010; 48: 1457-1464.

4. Kaneko H, Inoue K, Tominaga Y, et al. Damping performance of polymer blend/organic filler hybrid materials with selective compatibility. Mater Lett 2002; 52: 96-99.

5. Yanbing W, Mingming Z, Ying L, et al. Mechanical and damping properties of glass fiber and mica-reinforced epoxy composites. Polymer Plast Tech Eng 2012; 51: 840-844.

6. Li SC, Qiu QW and Jarvela P. Studies on damping properties of $\mathrm{P}(\mathrm{MMA}-\mathrm{AN}) / \mathrm{P}(\mathrm{EA}-\mathrm{nBA})$ LIPNs. $J$ Appl Polymer Sci 2000; 75: 722-727.

7. Wong DTH and Williams HL. Dynamic mechanical and vibration damping properties of polyurethane compositions. J Appl Polymer Sci 1983; 28: 2187-2207.

8. Parvaiz MR, Thorat PV and Mahanwar PA. Dynamic mechanical analysis and morphological studies of fly ash/mica reinforced poly(ether-ether-ketone)-based hybrid composites. Polymer Compos 2014; 35: 68-78.

9. Araki K, Kaneko S and Matsumoto K. Comparison of cellulose, talc, and mica as filler in natural rubber composites on vibration-damping and gas barrier properties. Adv Mater Res 2013; 844: 318-321.

10. Hajime K, Manabu K, Satoshi M, et al. Damping properties of thermoplastic-elastomer interleaved carbon fiber-reinforced epoxy composites. Compos Sci Tech 2004; 64: 517-523.

11. Ajayan PM, Suhr J and Koratkar N. Utilizing interfaces in carbon nanotube reinforced polymer composites for structural damping. J Mater Sci 2006; 41: 7824-7829.

12. Nakaramontri Y, Kummerlöwe C, Nakason C, et al. The effect of surface functionalization of carbon nanotubes on properties of natural rubber/carbon nanotube composites. Polymer Compos 2015; 36: 2113-2122.

13. Merriman EA. Aramid pulp processing and properties for industrial papers. TAPPI J 1984; 67: 66-68.

14. Jinchun LI, Xiulan YOU, et al. Effect of added poly (vinyl pyrrolidone) during condensation on properties of poly(p-phenylene terephthalamide)pulp. J Donghua Univ 2009; 26: 147-153.

15. Downey JS, Tsimpris CW, et al. Study on Kevlar ${ }^{\circledR}$ para-aramid pulp reinforced rubber. Tire Ind 2012; 32: 417-422.
16. Tsimpris CW, Jakob JP and Vercesi GP. KEVLAR ${ }^{\circledR}$ engineered elastomer for tire reinforcement. In: International tire exhibition and conference, Akron, Ohio, 2002.

17. ISO 2393:2014(E). Rubber test mixes-preparation, mixing and vulcanizatio-Equipment and procedures. International Standard, 2014.

18. ASTM E756:2010. Standard test method for measuring vibration-damping properties of materials. ASTM International, 2010.

19. Qin CL, Zhao DY, et al. Vibration damping properties of gradient polyurethane/vinyl ester resin interpenetrating polymer network. Mater Chem Phys 2006; 97: 517-524.

20. ASTM D2084-2007a. Standard test method for rubber property-vulcanization using rotorless cure meters. ASTM International, 2007.

21. ASTM D412 - 06a (Reapproved 2013). Standard test methods for vulcanized rubber and thermoplastic elastomers - tension. ASTM International, 2013.

22. Finegan IC and Gibson RF. Recent research on enhancement of damping in polymer composites. Compos Struct 1999; 44: 89-98.

23. Ward IM and Klein PG. Polymer physics. John Wiley \& Sons, Ltd, 2007, pp.98-99. DOI: 10.1002/9780470034590. emrstm0404.

24. Wu CF. Interphase migration of a hindered phenol compound in acrylate rubber/chlorinated polypropylene blends. Polym J 2003; 35: 286-289.

25. Li YY. Para-aramid short fiber (Kevlar engineering elastomer) for rubber reinforcement. Adv Rubber Tech 2007; 4: 1-8.

26. Cremer L and Heckl M. Structure-borne sound. Berlin: Springer, 1988.

27. Liu Q, Li M, Gu Y, et al. Interlocked CNT networks with high damping and storage modulus. Carbon 2015; 86: 46-53.

28. $\mathrm{Wu} \mathrm{CF}$, et al. Viscoelastic properties of an organic hybrid of chlori2nated polyethylene and a small molecule. J Polymer Sci B Polymer Phys 2000; 38: 134121347.

29. $\mathrm{Wu} \mathrm{CF}$, et al. Phase modification of acrylate rubber/ chlorinated polypropylene blends by a hindered phenol compound. Polymer J 2001; 33: 3222329.

30. Wu CF, et al. Dynamic properties of an organic hybrid of chlorinated polyethylene and hindered phenol compound. J Appl Polymer Sci 2001; 82: 178821793.

31. Wu CF, et al. Organic hybrid of chlorinated polyethylene and hindered phenol (II) Influence of the chemical structure of smallmolecules on viscoelastic properties. J Polymer Sci B Polymer Phys 2000; 38: 149621503.

32. Liu Q, Ding X, et al. The influence factors of the dynamic mechanical properties of organic hybrid damping material. Fiber Reinf Plast Compos 2007; 02: 54-58. 